\title{
Genetic epidemiology of multiple sclerosis
}

\author{
Alastair Compston
}

Epidemiological studies of multiple sclerosis have been performed on almost an industrial scale over the past 90 years. Morbidity statistics have been used to generate aetiological hypotheses, to assess local needs for the provision of services and the allocation of resources, and to define the natural history of the disease. Methodological factors have limited the extent to which the many surveys have yielded definitive conclusions in any one of these contexts. Most vulnerable have been the comparisons of prevalence between regions and the serial studies of single places.

In planning an epidemiological study in multiple sclerosis, the usual practice is to retrieve cases from lists of those already known to be affected. Because in most parts of the world the diagnosis is coordinated through hospital clinics, scrutiny of departmental and office notes provides the best source of information. In some situations, a case can be made for retrospectively adjusting statistics to include those people who would have featured in a population based survey if their whereabouts or clinical status had been known at the time (onset adjusted prevalence ${ }^{1}$ ); their exclusion can then be regarded as an error of administration, recognition, disease expression, or any one of the quirks which makes one person seek medical advice in advance of another. Rigid application of criteria for inclusion, and the decision to omit suspected cases, will vary depending on the purposes of the study. For surveys examining biological features, the error should be towards inclusion of those who probably have the disease process even if this is not yet clinically declared. In other contexts, it is essential to restrict the register to those who definitely have the disease.

Cases of different racial origin should not be grouped because they may differ for important characteristics. Sociohistorical factors are known to create significant differences in risk status even across quite small regions; conversely, some questions relating to the epidemiology of multiple sclerosis, which involve cohort studies, can only be answered by comparing specifically different locations. It makes little sense to plan a study requiring the recruitment of significant numbers of patients with a rare manifestation of multiple sclerosis, such as twinning or familial disease, in a community which has a low overall prevalence of the disease. Similarly, a ubiquitous but biologically important feature may not differ significantly between groups in places where multiple sclerosis is relatively common. It follows that there are usually better opportunites for identifying risk factors which make a significant contribution to the disease but are frequent in the at risk population by working in areas of low prevalence; conversely, risk factors for multiple sclerosis which are not overrepresented in the normal population will be identified more easily in high prevalence regions.

The extent to which complete ascertainment is achieved depends much on the structure, size, and distribution of the denominator, and whether the population has previously been surveyed. The few patients with multiple sclerosis in a medium to low prevalence island community with a demographically stable population of around 20000 and a normal age structure, can easily be ascertained but when surveying the disease in one at risk group living within a large metropolitan but ethnically mixed community, it may prove impossible to ascertain with confidence either the numerator or denominator, especially if recent population censuses are not available. Improved provision of facilities for the disabled inflates both prevalence and mortality; and the arrival of an investigator with a special interest in the disease abruptly increases morbidity estimates although these will plateau once ascertainment is saturated. Underestimating the absolute number of cases may not affect the definition of geographical gradients in the distribution of multiple sclerosis but it does matter in serial studies of a single region where a rise in prevalence resulting from reduced mortality and altered diagnostic criteria has to be distinguished from a real increase in incidence. It follows that investigator vigilance is a major confounding factor in comparative epidemiology.

\section{Distribution of multiple sclerosis}

By the beginning of the 20th century, multiple sclerosis-a disease that merited individual case reports 25 years previously-had become one of the commonest reasons for admission to a neurological ward. The period 1900 to 1950 saw a gradual evolution of methods 
Figure 1 Distribution of multiple sclerosis in Scandinavia (Finland, Sweden, Norway, Denmark, and Iceland), central Europe (Holland, Switzerland, Austria, Germany, Hungary, Slovakia, Poland), France, Spain and Portugal, Italy, Malta, Greece, Albania, Croatia Romania, and Bulgaria; figures are prevalence/10 of the population.

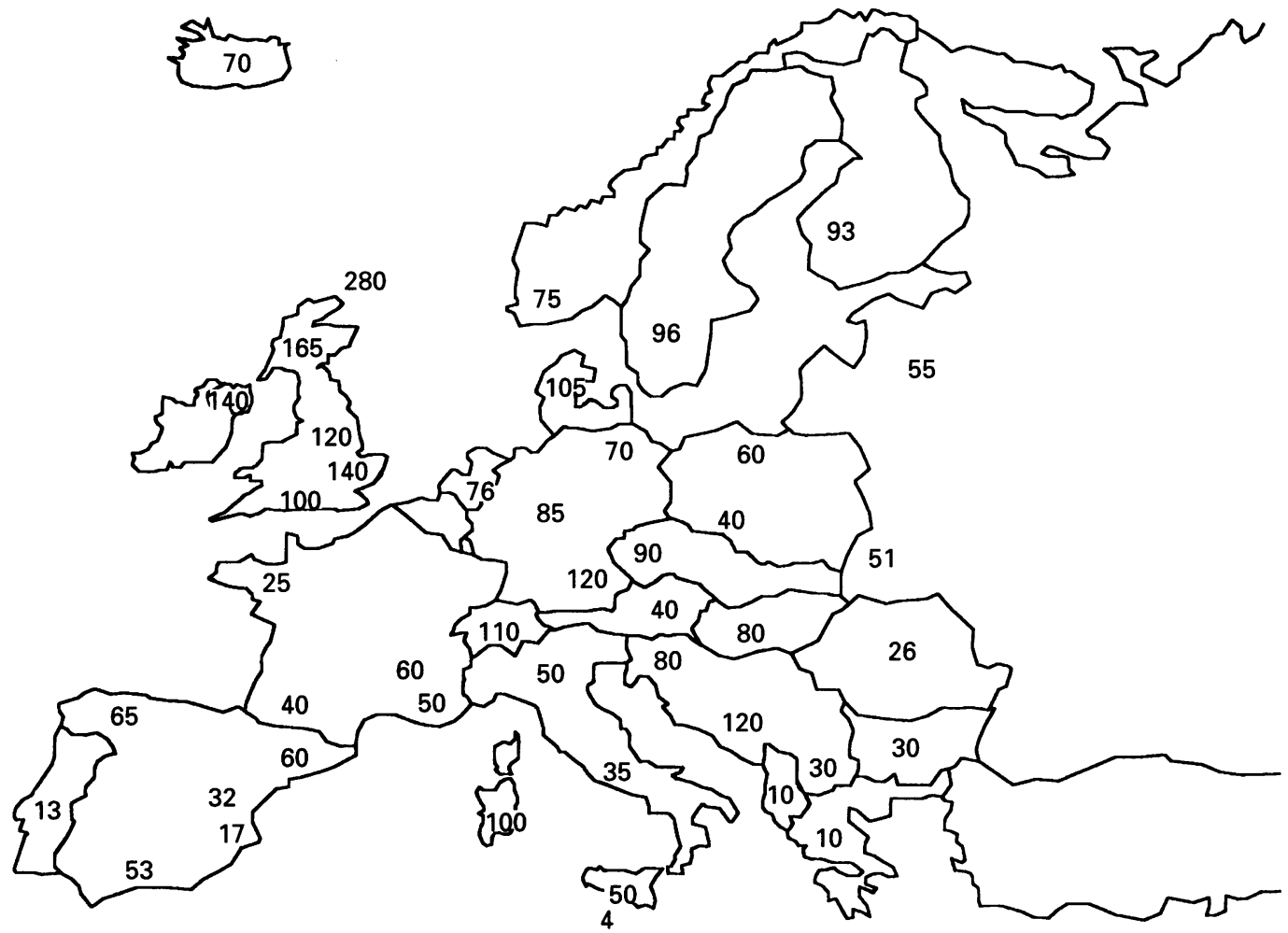

required for accurate definition of population based statistics; over the past four decades, surveys from most parts of the world have established the big picture on the geography of the disease and have allowed speculation on the reasons for its chacteristic distrbution.

Twenty years ago John Kurtzke, who has worked hardest to make sense of the epidemiological facts relating to multiple sclerosis, collated the published surveys of prevalence and suggested that the distribution could broadly be classified into bands of low, medium, and high prevalence. ${ }^{2-4}$ High risk $\left(>30 / 10^{5}\right)$ was found throughout northern Europe, the northern United States, Canada, southern Australia, and new Zealand; medium risk $\left(5-30 / 10^{5}\right)$ was found in southern Europe, the southern United States and northern Australia; and low risk $\left(<5 / 10^{5}\right)$ areas included

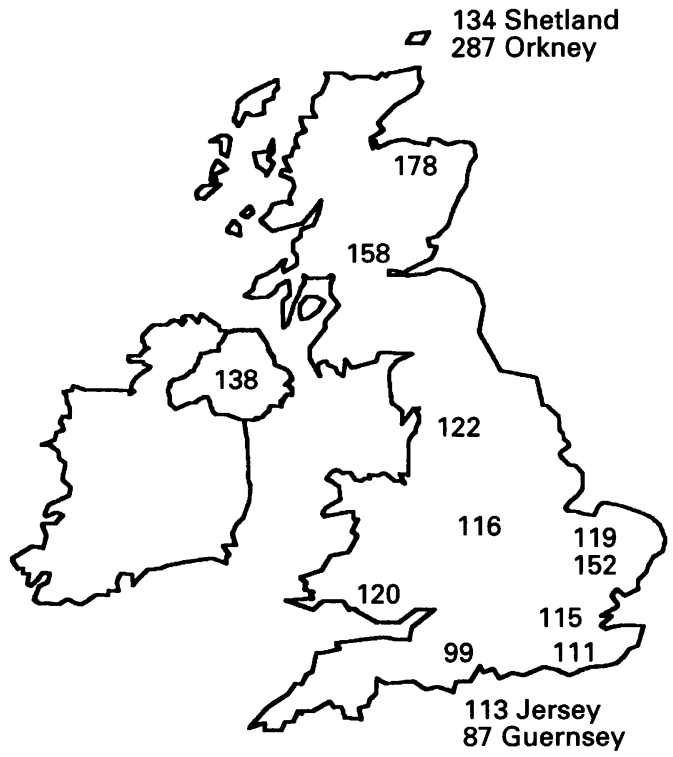

Asia, South America, and many uncharted regions. Systematic updating of these figures shows that the absolute number of cases identified in different parts of the world has risen steadily since the $1950 \mathrm{~s}^{5-7}$ Rather than catalogue all the surveys (now running to many hundreds) or describe the laborious evolution of the ideas on causation which flow from them, figs 1-4 depict surveys for the regional prevalences of multiple sclerosis in 1997 in Europe, the United Kingdom, North America and Canada, and Australasia: there is a relative paucity of information on incidence; indinor are $95 \%$ confidence intervals (95\% CIs) shown as these are not always provided in the original publications and some of the figures are a best guess. The figures for the United Kingdom in fig 1 are regional approximations for those given in fig 2 . What emerges from the more recent surveys is that many of the putative claims for latitudinal gradients were overstated but it remains the case that the disease does show variations in its distribution over quite small distances which may be informative with respect to ideas on the aetiology.

Multiple sclerosis is evidently a common disorder of young adults in northern Europe, continental North America and Australasia but not in the Orient, the Arabian peninsula, Africa, continental South America, and India (not all shown in the figures). Nevertheless, in northern Europe, prevalence (and incidence) are higher in southern Scandinavia, northern Germany, the United Kingdom and parts of Italy, than in northern Scandinavia, France, Spain, and the eastern Mediterranean countries. Within the United Kingdom, the disease is more prevalent in north east Scotland, and the Orkney and Shetland islands than in other parts of England, Wales, and Ireland.$^{8}$ In Italy, vidual sources of information are not cited; 


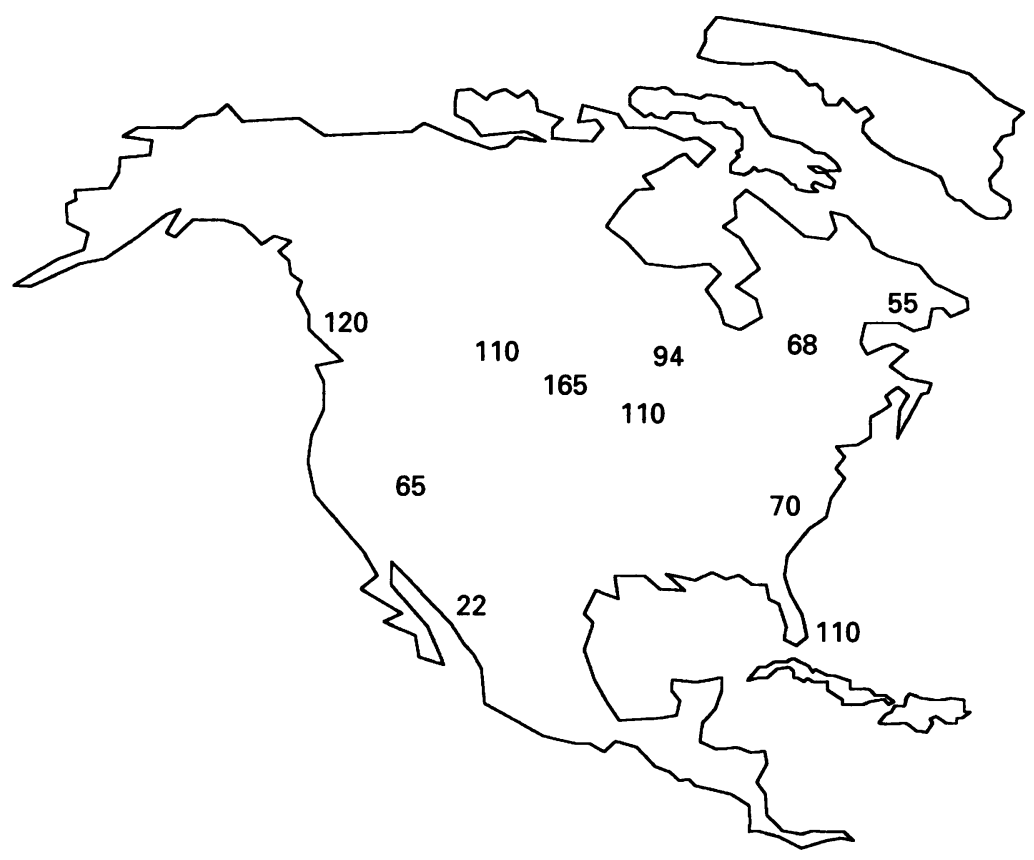

Figure 3 Distribution of multiple sclerosis in the United States and Canada; figures are prevalence/ $10^{5}$ of the population.

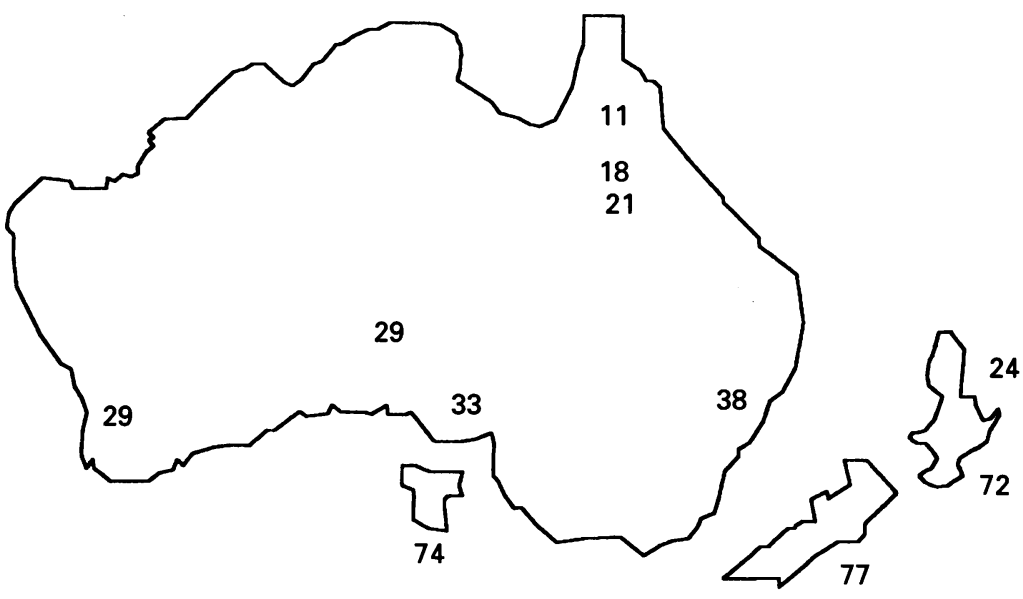

Figure 4 Distribution of multiple sclerosis in Australia and New Zealand; figures are prevalence $/ 10^{5}$ of the population. effect of migration has been to define multiple sclerosis as an acquired exogenous disorder.

Attention was first paid to comparisons of the frequency of multiple sclerosis between racial groups in a single geographical setting in South Africa during the 1950 s. Dean showed that age corrected frequency of the disease was highest in immigrants from Europe, low in Afrikaaners, and intermediate in South African English for both prevalence and incidence $^{12}$; the absolute absence of multiple sclerosis in African black people was confirmed but a slightly higher rate was seen in the Cape Coloured population, which has mixed African and European ancestry. Within the English speaking white population, those moving from northern Europe to southern Africa as adults took with them the high frequency of the country of origin, whereas those migrating younger than 15 years showed the lower rates characteristic of native born inhabitants of southern Africa.

No less influential has been the study of United Kingdom born children of immigrants from the Indian subcontinent, Africa, and the West Indies, ${ }^{13} 14$ which showed that the prevalence of multiple sclerosis in the United Kingdom born children of West Indian, African, and Asian immigrants approximates to that seen in similar age groups among the white population. Although methodological difficulties arise in this study of an ethnic minority living in a large metropolis, there are several reasons for suspecting that the number of patients with multiple sclerosis, born in the United Kingdom of parents who were migrants from the West Indies, Africa, or Asia, has actually been underascertained. However, the danger of extrapolating from studies involving a small numerator living in an unusual environment is well illustrated by the study of multiple sclerosis among immigrants from Vietnam to Paris, France. ${ }^{15}$ Three cases were identified among a cohort of around 3400 persons born of Vietnamese mothers who came to France under the age of 20 years. The fact that the cumulative 18 year risk of multiple sclerosis, by 1975 , was $89 / 10^{5}(95 \%$ CI 18-260), with an age specific prevalence of $169 / 10^{5}$ (95\% CI 94-135) in the third decade actually tells us nothing about the shift in risk of the disease consequent on movement of people from southern Asia to northern France as, apart from the wide confidence intervals, having a French born father was a requirement for immigration; genetic admixture therefore introduced an essential bias into this study.

Another classic series of epidemiological studies compared the frequency of multiple sclerosis among Japanese in Hawaii, the west coast of North America, and Japan. In Hawaii, the prevalence among Japanese was $7 / 10^{5}$ compared with $34 / 10^{5}$ in white immigrants to Hawaii ${ }^{16-18}$; these rates were virtually identical for Japanese and white people living in California $^{19}$ and can be compared with the expected rate of $2 / 10^{5}$ for native Japanese. ${ }^{20}$ Here, the evidence favours a strong protective effect for the Japanese irrespective of environment. 
The other location where migration has occurred on a sufficient scale to show important age related differences in prevalence of multiple sclerosis is Israel. The original study in immigrants reported a difference in prevalence between migrants from northern Europe (Ashkenazi Jews) and from Asia and Africa (Sephardic Jews). ${ }^{2122}$ The higher frequency in Ashkenazi than Sephardic Jews also showed an age at migration effect, in that there were very few Ashkenazis in the cohort arriving in Israel before adolescence. Although crude rates retained the difference seen in the parental groups, prevalence in the Israeli born children of Ashkenazi and Sephardic Jews was the same after age adjustment to the population of the United States. These important studies have recently been updated ${ }^{23}$; depending on place of paternal birth, prevalence (age adjusted to the Israeli population of 1960) was estimated at 32 (fathers born in Israel), 38 (fathers born in Europe or North America), and 29 (fathers born in Africa or Asia) compared with $14 / 10^{5}$ in immigrants. Higher rates were found in Jerusalem $\left(61,68\right.$, and $51 / 10^{5}$ for Israelis with Israeli, European/American, and African/ Asian fathers respectively) than in other parts of the country. The implication is that, at least for Ashkenazi and Sephardic Jews, racially determined differences in risk for multiple sclerosis are modified by environment.

Movements within one continent or country are also informative for the assessment of risk depending on time spent in regions of differing prevalence. A study of United States citizens showed that mortality for southern born patients dying in the north was $0.68 / 10^{5} /$ year compared with $0 \cdot 46 / 10^{5} /$ year for those remaining in the south. The mortality ratio for United States army veterans born in the high frequency northern states and entering military service from the middle zone dropped from 1.48 to 1.27 , and to 0.74 for those entering from the southern states. Those born in the medium risk zone showed a ratio increase in frequency of multiple sclerosis to 1.4 if entering military service from the north and a reduced ratio of 0.73 if entering from the south. ${ }^{24}$

All of these studies proved enormously influential in shaping ideas on the contribution of environmental factors to the aetiology of multiple sclerosis. Having established from the migration studies and analyses of epidemics that environmental factors probably do alter the risks of developing multiple sclerosis, and may override racial susceptibility, it became important to establish at what age these influences occur. Clearly, the critical period is before clinical onset and the studies from South Africa and the United States veterans' survey suggest that, in all probability, the disease process is established in childhood but few would be confident about confining risk to a particular calender age.

As part of a national survey of multiple sclerosis in France, 246 persons were identified who had migrated from north Africa in the first quinquennium of the 1960s after the Algerian war for independence, among 8000 cases ascertained overall in France. ${ }^{25}$ Excluding the 27 patients who had multiple sclerosis before, or at the time of migration, $86 \%$ of these 246 probands were European in origin and the remainder Arab or Berber. There was no apparent age or sex adjusted difference in frequency or mean age at onset between these and native French cases and this has been interpreted as indicating that the provocative exogenous factors are ubiquitous and that multiple sclerosis is acquired by the same age in each group. As far as this study is concerned, Kurtzke considers that matching by age has introduced a confounding factor as this will have restricted individual subjects to those with the same age at onset; he prefers the interpretation that in this cohort there is a fixed interval between migration and clinical onset, regardless of age, and takes the study to provide evidence for susceptibility extending to people in the mid- $40 \mathrm{~s}$. ${ }^{7}$ However, a range of more than 30 years could be considered not to provide much insight into the critical age of exposure to the putative agent which causes multiple sclerosis.

\section{Epidemics of multiple sclerosis}

Those who espouse the environmental doctrine of multiple sclerosis are naturally enthusiastic about epidemics of the disease. The arguments put forward by Kurtzke ${ }^{7}$ for point source epidemics, especially that proposed for the Faroe Islands, have not been universally accepted and others take the view that these are epidemics of recognition reflecting the arrival of specialist medical services in island communities rather than a genuine change in incidence arising from the introduction of transmissible aetiological factors into virgin populations.

In the first survey of Iceland, 168 cases of multiple sclerosis were identified with onset between 1900 and $1975 .{ }^{26}$ Annual incidence rates seemed to rise around 1922; they then stabilised until a further increase occurred in 1945 , heralding a steady decline from the mid1950s. Each quinquennial rate for incidence from 1900 was lower than between 1945 and 1954, during which age at onset was also younger than before or after this period. This led to the conclusion that there had been a postwar epidemic of multiple sclerosis in Iceland ${ }^{2627}$ but opinions differ both with respect to the facts and their interpretation. John Benedikz, an Icelandic neurologist who has taken a particular interest in the epidemiology of multiple sclerosis, favours the view that any change in frequency of multiple sclerosis in Iceland during the 20 th century should be attributed to improved recognition and diagnostic procedures rather than increased incidence. ${ }^{128}$ In support of this interpretation, Benedikz et al have reviewed 323 patients with onset of symptoms attributed to multiple sclerosis after 1 January 1900 of whom 252 were still living in December $1989 .{ }^{29}$ Incidence rates were $<1 / 10^{5} /$ year up until the 1930 s but then increased to $2 \cdot 5 / 10^{5} /$ year, coinciding with the arrival of two neurologists. With waning 
enthusiasm, so the analysis goes, there was then a lull between 1945 and 1955, when incidence increased to $3 \cdot 3 / 10^{5}$ year after the first systematic survey of the disease. With nine neurologists in practice from 1975, there was a further increase to a peak incidence of $4 \cdot 1 / 10^{5} /$ year, which is being maintained. Benedicz et al argue that case ascertainment in the era before 1950 was far from adequate as shown by the long interval at that time between onset and diagnosis, with a paucity of milder registered cases, and comparisons of disability in the affected cohorts showing an overloading of those with severe multiple sclerosis before 1950 . The abrupt reduction in interval between onset and diagnosis after 1940 is seen as further evidence for the impact of neurological expertise on early diagnosis and improved case ascertainment.

The original findings on multiple sclerosis in the Faroe islands ${ }^{3031}$ showed fewer cases than expected from comparisons with neighbouring Orkney and Shetland. Kurtzke ${ }^{7}$ searched many places in his attempt to trace cases back to before the second world war but in neither the initial survey ${ }^{31}$ nor later assessments ${ }^{32-35}$ was any patient identified with an estimated date of onset earlier than 1943. There were then 16 cases with onset between 1943 and 1949, a further 16 developing clinical manifestations between 1950 and 1973 and, by 1986,41 patients had been ascertained of whom nine had lived abroard for three or more years and so were not considered directly to have been part of the epidemic. Kurtzke concludes that the critical factor determining the Faroes experience of multiple sclerosis was occupation by British troops between 1940 and 1945, the development of multiple sclerosis showing both a temporal and spatial relation in that villages where people lived who contributed to each of the incidence peaks were also those where troops were billeted. But some are not convinced by this analysis ${ }^{36} 37$ despite robust counter claims from the main protagonists with respect to specific criticisms concerning validity of the diagnoses, exclusions, case ascertainment, definition of epidemics, and the putative role of the British occupation in the genesis of this cluster. ${ }^{735}$

In the Orkney and Shetland Islands, the incidence and prevalence of multiple sclerosis were at one time higher, almost by an order of magnitude, than in other regions. Estimates of prevalence carried out on four occasions between 1954 and 1974 showed a steady rise in frequency from $111 / 10^{5}$ in 1954 to $309 / 10^{5}$ in 1974 for Orkney, and from $134 / 10^{5}$ to $184 / 10^{5}$ in Shetland over the same period. ${ }^{838}$ Comparison of incidence and mortality confirms the impression that there has been no significant alteration in statistics for the disease other than those attributable to changes in classification and ascertainment. Over the period of these studies, systematic depopulation in Orkney and Shetland left an older population less at risk of multiple sclerosis and, as elsewhere, the rise in prevalence can best be attributed to increased survival (from 26 to 40 years in Orkney and from 24-34 years in
Shetland between 1954 and 1974) and improved case recognition. The question of serial change in incidence for multiple sclerosis in Orkney has since been revisited; although there had been a steady reduction from 1964, prevalence figures for 1994 were $287 / 10^{5}$ (probable and definite cases) and $134 / 10^{5}$ for Orkney and Shetland respectively (S Cook, personal communication). These statistics show that although there has been significantly less multiple sclerosis in Shetland since 1965, this is no longer true for Orkney.

An epidemic has been claimed for Key West, a tropical island off the west coast of Florida where 37 patients with peak onset in and around 1977-9 were identified in 1984 (prevalence 140/105) - an increase that could not be attributed to alterations in clinical vigilance or differential migration of symptomatic persons to a more favourable climate. ${ }^{39}$

\section{Factors which predict the clinical course}

Apart from surveys which have assessed highly selected populations of patients, multiple sclerosis is almost always found to be more common in females than in males. The reported figures vary but a sex ratio of two females : one male is usual, irrespective of ethnicity ${ }^{4041}$; in children, the excess of females is even more pronounced $^{42}$ whereas multiple sclerosis presenting in or beyond the fifth decade more commonly affects males. ${ }^{4041}$

At diagnosis, many patients with multiple sclerosis want information on the prognosis. So-called benign multiple sclerosis is characterised by young age at onset, usually occurring in females with infrequent sensory episodes which recover fully; conversely, the prognosis is more predictably gloomy in males with older age of onset and a progressive course involving motor systems. The influence of attack rate early in the disease on outcome has been somewhat less clear. Whereas all neurologists will be familiar with patients in whom a brisk start to the disease with several nasty attacks settled down into a much more favourable middle and long term course than had at first seemed probable, the large population based studies have shown that attack rate in the early years is of some prognostic value. 404143

Trauma as a trigger of disease activity in multiple sclerosis has been much considered, and still features in the law courts, where plaintiffs may claim that an accident has provoked the first appearance of multiple sclerosis or altered the course of pre-existing manifestations. Sibley et al $^{44}$ prospectively studied disease activity by questionnaire and physical examination for eight years. Taking either the three or six month period after each event as at risk, only electrical trauma showed an association with new episodes; all other noted forms of trauma were negatively correlated both with clinical exacerbations and disease progression. Siva et $a l,{ }^{45}$ using the Mayo Clinic cohort, also conclude that disease exacerbations are no more frequent in the six months after limb fracture than at other times. 
The situation with respect to the risk from anaesthesia is unsatisfactory in that no epidemiologically based studies have been performed and the evidence is entirely anecdotal; some neurologists advise patients to avoid elective interventions while remaining sensible about treatments or procedures which justify the small risk of increasing disease activity-if it actually exists. ${ }^{46} 47$

Several authors have shown prospectively that new episodes of demyelination increase after (presumed) viral exposure but no single agent has been implicated ${ }^{48} 49 \%$ of presumed infections are followed by relapse and $27 \%$ of new episodes are related to infection; the relative risk for relapse in the four week period after upper respiratory (especially adenovirus) or gastrointestinal infections is $1 \cdot 3$.

Anecdotal evidence on whether pregnancy affects the immediate or long term course of multiple sclerosis has now been supplemented by prospective surveys which indicate that the onset of multiple sclerosis does not cluster around pregnancy, and that having children does not alter the long term course of the disease but there is an increase in relapse rate during the puerperium. However, a major confounder in the detailed interpretation of these studies is the decision by women with severe disability not to embark on pregnancy and the corresponding preparedness of those with mild disease to start or extend their families. The prospective studies indicate a roughly threefold higher risk in the three to six months after term than during pregnancy, ${ }^{50}{ }^{51}$ and suggest that the attacks may be more severe. ${ }^{52}$ There is less agreement on whether or not the relapse rate is maintained or falls during the pregnancy itself, as was suggested in several of the retrospective surveys. ${ }^{53-55}$ In the most comprehensive epidemiological analysis of issues relating to multiple sclerosis and pregnancy, Runmarker and Andersen ${ }^{56}$ studied an inception cohort in Goteborg, Sweden and disposed of the hypothesis that the onset of multiple sclerosis is influenced by pregnancy; there was a conspicuous absence of onset bouts during pregnancy compared with non-pregnant epochs including the puerperal eight months. Fecundity was reduced in women with multiple sclerosis, presumably by choice, especially in the context of significant disability and this is the probable explanation for the conclusion that pregnancy after onset is associated with a lower risk of progression.

\section{Familial multiple sclerosis}

Multiple sclerosis has a familial recurrence rate of about $15 \%$ and it is usually assumed that this is due to coinheritance of susceptibility factors, but the alternative hypothesis is that this results from common exposure to environmental factors in childhood. The most comprehensive study of recurrence (from Canada) takes as its baseline a lifetime risk of $0.2 \%$ for the entire population, and shows an increase to $3 \%$ in other first degree relatives (relative risk 20 ) and $1 \%$ in second degree relatives (relative risk $5 \cdot 5) .{ }^{57}$
Comparable studies from the United Kingdom confirm that the highest age adjusted recurrence rate is for sisters $(4 \cdot 4 \%)$ and brothers $(3 \cdot 2 \%)$, compared with parents $(2 \cdot 1 \%)$ and offspring $(1 \cdot 8 \%)$. Overall, the reduction in risk changes from $2 \cdot 8 \%$ (relative risk $9 \cdot 2$ ) in first degree relatives to $1.0 \%$ (relative risk 3.4 ) and $0.9 \%$ (relative risk 2.9 ) in second and third degree relatives, respectively, compared with a background age adjusted risk in this population of $0.3 \% .^{58}$ In Flanders, the recurrence risks are 10-fold to 12-fold for first degree and threefold for second degree relatives. ${ }^{59}$

With some variations in methodology, three recent studies approximate to a population based series of multiple sclerosis in twins. ${ }^{60-63}$ Two show remarkable consistency in demonstrating a higher clinical concordance rate in monozygotic twins (about $25 \%$ ) than dizygotic pairs (about 3\%); the French study is exceptional in showing no significant difference between monozygotic and dizygotic twins but critics have argued that this result is within the confidence limits of the other surveys. The relative risk for multiple sclerosis in the monozygotic twin partner of an affected proband is therefore about 190 .

Adopted persons who subsequently develop multiple sclerosis, and affected people who have themselves adopted children provide an unusual but informative resource for studying the relative contribution of genes and the environment in the aetiology of multiple sclerosis. Considering those with multiple sclerosis who are adopted before the age of one year, and those with multiple sclerosis who through adoption have non-biological siblings or children, the frequency of multiple sclerosis in non-biological parents, siblings, and children is more or less identical to the population prevalence and lifetime risk for Europeans, and significantly lower than that expected from the study of recurrence risks in the biological relatives of index cases. ${ }^{64} \mathrm{Half}$ siblings offer yet one more variant on the familial multiple sclerosis theme in that they share a proportion of parental genes and divide into those who are reared together and apart, at least during the period which is thought critical for the development of multiple sclerosis. The age adjusted risk for half siblings is significantly lower than for full siblings and there is no difference in risk for half siblings reared together and apart. ${ }^{65}$

Conjugal pairs with multiple sclerosis who have children provide a special opportunity for assessing the contribution made to susceptibility by genetic factors. Five of 86 offspring from 45 conjugal pairs living in the United Kingdom were shown also to have multiple sclerosis and a further five had either characteristic imaging abnormalities or clinical symptoms consistent with demyelination but did not meet the criteria for clinically definite disease; the recurrence risk (crude 1 in 17: age-adjusted 1 in 5) is obviously much higher than the risk for the children of single affected patients (crude 1 in 200: age adjusted 1 in 50). ${ }^{66}$ Conjugal pairs can also be used to assess the influence of environmental factors in determin- 
Northern Europeans (1:600)

000000000000000000000000000000000000000000000000000000000000 000000000000000000000000000000000000000000000000000000000000 000000000000000000000000000000000000000000000000000000000000 000000000000000000000000000000000000000000000000000000000000 000000000000000000000000000000000000000000000000000000000000 $0000000 \bullet 0000000000000000000000000000000000000000000000000000$ 000000000000000000000000000000000000000000000000000000000000 000000000000000000000000000000000000000000000000000000000000 000000000000000000000000000000000000000000000000000000000000 000000000000000000000000000000000000000000000000000000000000

Child [one affected parent] (1:200)

0000000000000000000000000000000000000000

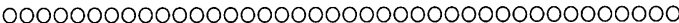
$0000000000000000000000000000000000 \bullet 00000$ 0000000000000000000000000000000000000000 0000000000000000000000000000000000000000

Affected sibling/dizygotic twin (1:40)
00000000000000000000 00000000000000000000

Child [conjugal parents] (1:17) $00000000000 \bullet 00000$

Affected monozygotic twin (1:3)

$\mathrm{O} 0 \mathrm{O}$

Class 2 MHC Association (DRw15/DQw6)

$\mathrm{T}$ cell receptor $\mathrm{V}$ beta 8 polymorphism or

Ig $\mathrm{Vh}$ region polymorphism (each $\mathrm{c1:150)}$

00000000000000000000000000000000000000000000000000 0000000000000000000000000000000000000000000000000 00000000000000000000000000000000000000000000000000

Class 2 MHC Association (DRw15/DQw6)

TCR V beta 8 polymorphism (c1:60)

000000000000000000000000000000

000000000000000000000000000000

New regions from genome screens (1:25)

00000000000

000000000000

Figure 5 Scheme to show the reduction in crude risk for multiple sclerosis depending on relation to the proband and the presence of defined susceptibility factors. Comparable age adjusted figures are: children of single affected parents 1 in 50; siblings 1 in 30; children of conjugal pairs 1 in 5; monozygotic twins 1 in 2.

ing the onset and course of multiple sclerosis. In the United Kingdom survey, there was no evidence for clinical concordance, clustering at year of onset, or distortion of the expected pattern of age at onset in the second affected spouse from 33 pairs in whom these comparisons could be made. ${ }^{66}$ Figure 5 summarises these risks.

\section{Markers of genetic susceptibility}

The change in recurrence risk seen between twins and first and second degree relatives suggests the independent or epistatic effects of more than one gene; the modest trend for affected pairs to be female hints at a contribution of sex independent of genes; the low concordance rate, even among monozygotic pairs, indicates a significant independent or modifying effect of the environment on expression of genetic susceptibility.
These findings have stimulated attempts to identify and locate the genes which confer susceptibility to the disease. Population studies have shown an association between the class II MHC alleles DR15 and DQ6 and their corresponding genotypes DRB1* 1501 , $\mathrm{DRB} 5{ }^{\star} 0101$ and $\mathrm{DQA1}{ }^{\star} 0102$, DQB2 ${ }^{\star} 0602 .{ }^{67}$ An extensive search, using association and linkage studies, has only yielded additional putative candidate genes in the VH2-5 immunoglobulin heavy chain and the $\mathrm{T}$ cell receptor $\beta$ chain variable regions. ${ }^{68-71}$ But the contribution to susceptibility made by the genes which have provisionally been identified, even if their effects are interactive, can only account for a proportion of the increased risk of multiple sclerosis implicated by family studies; and it seems likely that other genes which make an even greater contribution to susceptibility remain to be identified.

Three groups of investigators have now undertaken a systematic search of the genome in an attempt to locate additional susceptibility genes using affected family members-usually identity by descent analysis in sibling pairs. Genotyping was completed on cohorts each of between 75 and 225 families, together involving in excess of 1000 members, for each of between 257-443 microsatellite markers. These markers were chosen to have an average spacing of around $10 \mathrm{cM}$ giving enough power to identify regions encoding a major susceptibility gene; and they are sufficiently polymorphic to make a high proportion of the available families fully informative. Superficially, the results show a disappointing lack of overlap. The importance of HLA is confirmed but of the other new regions of interest, several are clearly unique to each screen and so may be false positives. The regions of interest emerging from the United Kingdom genome screen $^{72}$ are 1 cen, 5 cen, $6 \mathrm{p}, 7 \mathrm{p}, 14 \mathrm{q}, 17 \mathrm{q}$, $19 q$, and $X p$; they are $2 p, 3 p, 5 p, 11 q$, and $X p$ in the Canadian series ${ }^{73}$ and $6 \mathrm{p}, 7 \mathrm{q}, 11 \mathrm{p}, 12 \mathrm{q}$, and $19 q$ in the United States/French survey. ${ }^{74}$ Despite inconsistencies between the samples, it remains possible that meta-analysis will provide stronger evidence implicating one or more of these provisional areas of linkage, and the hope is that many of the false positive leads will be eliminated while larger clinical resources are deployed and new strategies pursued for detecting both linkage and new associations within families.

\section{Analysing the epidemiological pattern in multiple sclerosis}

The complex interplay of nature and nurture is reflected in the distribution of many diseases; some, such as malaria and the haemoglobinopathies, are reasonably well understood, but factors which determine the geography of complex traits remain much more enigmatic. As parts of Europe and North America were repeatedly surveyed for incidence and prevalence of multiple sclerosis over several decades, neuroepidemiologists began to polarise their views on the emerging patterns around the race versus place debate. 
Especially influential were the serial surveys of stable populations, and the epidemiologically less robust studies of small island populations. It was rapidly pointed out that the gradients in frequency within northern Europe, North America, and Australia compared with other parts of the world implicate an environmental factor in the aetiology of multiple sclerosis which is not ubiquitously distributed. The surveys of multiple sclerosis in northern Europeans migrating west to east provided crucial information implicating the role of environmental factors in shaping the distribution of the disease because, with the exception of Canada, parts of the world colonised from northern Europe show prevalence rates that are lower than in the country of origin. Considerable effort was therefore devoted to a systematic assessment of environmental factors in the hope that a relatively simple causative event would be identified leading to a strategy for eradication of the disease but none was found using either population serology or the most complex methods for virus detection which molecular biology can offer. With time it became clear that more complex patterns of distribution exist within continents and countries, and even across small regions. The evolving epidemiological features of multiple sclerosis made it necessary for epidemiologists to construct ever more elaborate hypotheses to account for the distribution of the disease. Thus there were claims for a role for climate, diet, geomagnetism, and toxins in addition to the infective aetiology.

The migration studies indicate that the risk of multiple sclerosis in a single ethnic group varies with place of residence during a critical period in childhood. However, migration does not just involve the movement of people; gene transfer and population stratification also follow. Failure to define the environmental cause of multiple sclerosis therefore led others to interpret the distribution of multiple sclerosis as a function of genetic susceptibility. ${ }^{107576}$ Each of these commentators concluded that multiple sclerosis is to be found where there are northern European genes. It was further suggested that the increased risk of the disease in native people moving out of Africa to the United States correlates with the extent to which white genes are introduced into the black community ${ }^{77}$; and some at least of the affected children of West Indian immigrants to the United Kingdom are known to have white British or Irish ancestors.

The best supporting evidence that markers of susceptibility to multiple sclerosis show much the same geographical patterns as the disease itself comes from the construction of detailed genetic maps which include information on clines for HLA-B7, ${ }^{78}$ known to be associated in most populations with an increased risk of multiple sclerosis; presumably the same is true for DR15 and DQ6. As a consequence of sociohistorical events and population migrations, genes with a high frequency in the migrating populations necessarily become concentrated in small isolates whereas others are excluded, thus adding relic groups to the global pattern that exists for many polymorphic genetic markers, and the phenotypically more obvious distributions of language and anthropometrics.

By contrast with the interpretations offered by genetic epidemiologists, backed by evidence from population genetics, environmentalists must still leave the facts to speak for themselves as the case for an environmental agent as the dominant cause of multiple sclerosis remains stubbornly circumstantial. On the basis of the putative epidemic of multiple sclerosis in the Faroes, Kurtzke ${ }^{7}$ concludes that multiple sclerosis originated in Scandinavia (central Norway or the southcentral lake district of Sweden) in the early 18th century and diffused across the Baltic states and northern Europe including the British Isles over the next 100 years. From there, it was exported to north America and Australasia, to South Africa and Italy. The theme is familiar but whereas for Kurtzke the factors being distributed are germs, for others they are genes. ${ }^{79}$

1 Poser CM, Benedikz J, Hibberd PL. The epidemiology of multiple sclerosis: the Iceland model. Onset-adjusted prevalence rate and other methodological considerations. prevalence rate and other method
$¥$ Neurol Sci 1992;111:143-52.

2 Kurtzke JF. A reassessment of the distribution of multiple sclerosis. Part one. Acta Neurol Scand 1975;51:110-36.

3 Kurtzke JF, A reassessment of the distribution of multiple sclerosis. Part two. Acta Neurol Scand 1975;51:137-57.

4 Kurtzke JF. Geography in multiple sclerosis. F Neurol 1977;215:1-26.

5 Bauer HJ. Multiple sclerosis in Europe. Symposium report. f Neurol 1987;234:195-206.

6 Lauer K, Firnhaber W. Multiple sclerosis in Europe: an epidemiological update. Darmstadt: Leuchturm-Verlag/LTV Press, 1994:350.

7 Kurtzke JF. Epidemiologic evidence for multiple sclerosis as an infection. Clin Microbiol Rev 1993;6:382-427.

8 Robertson NP, Compston DAS. Surveying multiple sclerosis in the United Kingdom. I Neurol Neurosurg Psychiatry 1995;58:2-6.

9 Rosati G. Descriptive epidemiology of multiple sclerosis in Europe in the 1980s: a critical overview. Ann Neurol Europe in the 1980s: a criti
1994;36(suppl 2):S164-74.

10 Bulman D, Ebers GC. The geography of multiple sclerosis reflects genetic susceptibility. Fournal of Tropical and Geographical Neurology 1992;2:66-72.

11 Hammond SR, McLeod JG, Millingen KS, Stewart-Wynne EG, English D, Holland JT, McCall MG. The epidemiology of multiple sclerosis in 3 Australian cities: Perth, Newcastle, and Hobart. Brain 1988;111:1-25.

12 Dean G. Annual incidence, prevalence, and mortality of MS in white South African-born and in white immigrants to South Africa. BMF 1967;ii:724-30.

13 Elian $M$, Dean $G$. Multiple sclerosis among United Kingdom born children of immigrants from the West Indies. $\mathcal{F}$ Neurol Neurosurg Psychiatry 1987;50:327-32.

14 Elian M, Nightingale S, Dean G. Multiple sclerosis among United Kingdom-born children of immigrants from the Indian subcontinent, Africa, and the West Indies. $\mathcal{f}$ Neurol Neurosurg Psychiatry 1990;53:906-11.

15 Kurtzke JF, Bui QH. Multiple sclerosis in a migrant population to half orientals immigrating in childhood. $A n n$ Neurol 1980;8:256-60.

16 Alter M, Okihiro M, Rowley W, Morris T. Multiple sclerosis among orientals and caucasians in Hawaii. Neurology 1971;21:122-30.

17 Lauer K. The risk of multiple sclerosis in the USA in relation to sociogeographic features: a factor-analytic study. $\mathcal{F}$ Clin Epidemiol 1994;47:43-8.

18 Detels R, Brody JF, Edgar AH. Multiple sclerosis among American, Japanese, and Chinese migrants to California and Washington. $\mathcal{F}$ Chron Dis 1972;25:3-10.

19 Detels R, Visscher B, Malmgrem RM, Coulson AH, Lucia MV, Dudley JP. Evidence for lower susceptibility to multiple sclerosis in Japanese-Americans. Am $\mathcal{f}$ Epidemiol tiple sclerosis in

20 Kuroiwa Y, Shibasaki H, Ikeda M. Prevalence of multiple sclerosis and its north-south gradient in Japan. Neuroepidemiology 1983;2:62-9.

21 Alter M, Halpern L, Kurland LT, Bornstein V, Tikva P, Leibowitz U, Silberstein J. Multiple sclerosis in Israel: prevalence among immigrants and native inhabitants. Arch Neurol 1962;7:253-63.

22 Alter M, Kahana E, Loewenson R. Migration and risk of multiple sclerosis. Neurology 1978;28:1089-93. 
23 Kahana E, Zilber N, Abramson JH, Biton Y, Leibowitz Y, Abramsky $O$. Multiple sclerosis: genetic versus environmental aetiology: epidemiology in Israel updated. $f$ Neurol 1994;241:341-6.

24 Kurtzke JF, Kurland LT, Goldberg ID. Mortality and migration in multiple sclerosis. Neurology 1971;21: $1186-97$.

25 Delasnerie-Laupretre N, Alperovitch A. Migration and age at onset of multiple sclerosis in the pitfalls of migran studies. Acta Neurol Scand 1992;85:408-11.

26 Kurtzke JF, Gudmundsson KR, Bergmann S. Multiple sclerosis in Iceland. 1. Evidence of a post-war epidemic Neurology 1982;32:143-50.

27 Cook SD, Gudmundsson G, Benedikz J, Dowling PC. Multiple sclerosis and distemper in Iceland. 1966-78. Acta Neurol Scand 1980;61:244-51.

28 Benedikz JG, Magnusson H, Poser CM, Benedikz E, Olafsdottir G, Gudmundsson G. Multiple sclerosis in Iceland 1900-85. Fournal of Tropical Geographical Neurology 1991;1:16-22.

29 Benedikz JG, Magnusson H, Gudmundsson G. Multiple sclerosis in Iceland, with observations on the alleged epidemic in the Faroe Islands. Ann Neurol 1994;36(suppl 2):S175-9.

30 Allison RS. Some neurologic aspects of medical geography. Proc R Soc Med 1963;56:71-6.

31 Fog T, Hyllested K. Prevalence of disseminated sclerosis in the Faroes, the Orkneys, and Shetland. Acta Neurol Scand 1966;42(suppl 19):9-11.

32 Kurtzke JF, Hyllested K. Multiple sclerosis in the Faroe Islands: 1. Clinical and epidemiological features. $A n n$ Neurol 1979;5:6-21.

33 Kurtzke KF, Hyllested K. Multiple sclerosis in the Faroe Islands. II. Clinical update, transmission, and the nature of MS. Neurology 1986;36:307-28.

34 Kurtzke JF, Hyllested K. Multiple sclerosis in the Faroe Islands. III. An alternative assessment of the three epidemics. Acta Neurol Scand 1987;76:317.

35 Kurtzke JF, Hyllested K. Validity of the epidemics of multiple sclerosis in the Faroe islands. Neuroepidemiology 1988;7:190-227.

36 Poser CM, Hibberd PL, Benedicz J, Gudmundsson G. Analysis of the "epidemic" of multiple sclerosis in the Faroe Islands. I. Clinical and epidemiological aspects. Neuroepidemiology 1988;7:168-80.

37 Poser CM, Hibberd PL. Analysis of the "epidemic" of multiple sclerosis in the Faroe Islands. II. Biostatistical aspects. Neuroepidemiology 1988;7:181-9.

38 Cook SD, Cromarty MB, Tapp W, Poskanzer D, Walker JD, Dowling PC. Declining incidence of multiple sclerosis in the Orkney Islands. Neurology 1985;35:545-51.

39 Sheremata WA, Poskanzer DC, Withum DG, MacLeod CL, Whiteside ME. Unusual occurrence on a tropical island of multiple sclerosis [letter]. Lancet 1985 ;ii: 618 .

40 Weinshenker BG, Bass B, Rice GP, Noseworthy J, Carrier W, Baskerville J, Ebers GC. The natural history of multiple sclerosis: a geographicaly based study. 2. Predictive value of the early clinical course. Brain 1989;112: 1419-28.

41 Weinshenker BG, Bass B, Rice GP, Noseworthy J, Carriere W, Baskerville J, Ebers GC. The natural history of multiple sclerosis: a geographically based study. 3. Multivariate analysis of predictive factors and models of outcome. Brain 1991;114:1045-56.

42 Duquette P, Murray TJ, Pleines J, Ebers GC, Sadovnick D, Weldon $\mathrm{P}$, et al. Multiple sclerosis in childhood: clinica profile in 125 patients. $\mathcal{F}$ Pediatr 1987;3:359-63.

43 Runmarker B, Andersen O. Prognostic factors in a multiple sclerosis incident cohort with 25 years of follow up. Brain 1993;116:117-34.

44 Sibley WA, Bamford CR, Clark K, Smith MS, Laguna JF. A prospective study of physical trauma and multiple sclerosis. $\mathscr{F}$ Neurol Neurosurg Psychiatry 1991;54:584-9.

45 Siva A, Radhakrishnan K, Kurland LT, O'Brien PC Swanson JW, Rodriguez M. Trauma and multiple sclerosis: a population based cohort study from Olmsted County, Minnesota. Neurology 1993;43:1878-82.

46 Baskett PJF, Armstrong R. Anaesthetic problems in multiple sclerosis. Anaesthesia 1970;25:397-401.

47 Siemkowicz E. Multiple sclerosis and surgery. Anaesthesia 1976;31:1211-6.

48 Sibley, WA, Bamford CR, Clark K. Clinical viral infections and multiple sclerosis. Lancet 1985;i:1313-5.

49 Andersen $O$, Lygner P-E, Berstrom $T$, Andersson $M$, Vahlne A. Viral infections trigger multiple sclerosis relapses: a prospective seroepidemiological study. $\mathcal{F}$ relapses: a prospective
Neurol $1991 ; 240: 417-22$

50 Birk K, Ford C, Smeltzer S, Ryan D, Miller R, Rudick RA. The clinical course of multiple sclerosis during pregnancy and the puerperium. Arch Neurol 1990;47:738

51 Rouillet E, Verdier-Taillefer M-H, Amarenco P, Gharbi G Alperovitch A, Marteau R. Pregnancy and multiple scle- rosis: a longitudinal study of 125 remittent patients. $\mathcal{F}$ Neurol Nurosurg Psychiatry 1993;56:1062-5.

52 Worthington J, Jones R, Crawford M, Forti A. Pregnancy and multiple sclerosis-a 3 year prospective study. $\mathscr{F}$ Neurol 1994;241:228-33.

53 Korn-Lubetzki I, Kahana E, Cooper G, Abramasky O. Activity of multiple sclerosis during pregnancy and puerperium. Ann Neurol 1984;16:228-31.

54 Frith JA, McLeod JG. Pregnancy and multiple sclerosis. $\mathcal{F}$ Neurol Neurosurg Psychiatry 1988;51:495-8.

55 Bernardi S, Grasso MG, Bertollini R, Orzi F, Fieschi C. The influence of pregnancy on relapses in multiple sclerosis: a cohort study. Acta Neurol Scand 1991;84:403-6.

56 Runmarker B, Andersen O. Pregnancy is associated with lower risk of onset and a better prognosis in multiple sclerosis. Brain 1995;118:253-61.

57 Sadovnick AD, Baird PA, Ward RH. Multiple sclerosis; updated risks for relatives. Am f Med Genet 1988;29: 533-41.

58 Robertson NP, Fraser M, Deans J, Clayton D, Compston DAS. Age adjusted recurrence risks for relatives of patients with multiple sclerosis. Brain 1996;119:449-55.

59 Carton H, Vlietinck R, Debruyne J, De Keyser J, D'Hooghe M-B, Loos R, et al. Recurrence risks of multiple sclerosis in relatives of patients in Flanders, Belgium. $\mathcal{F}$ Neurol Neurosurg Psychiatry 1997;62:329-33.

60 Ebers GC, Bulman DE, Sadovnick AD, Paty DW, Warren $\mathrm{S}$, Hader W, et al. A population based study of multiple sclerosis in twins. N Engl f Med 1986;315:1638-42.

61 Sadovnick AD, Armstrong H, Rice GPA, Bulman D, Hashimoto L, Paty DW, et al. A population-based study of multiple sclerosis in twins: update. Ann Neurol 1993; 33:281-5.

62 French Research Group on Multiple Sclerosis. Multiple sclerosis in $\mathbf{5 4}$ twinships: concordance rate is indepensclerosis in 54 twinships: concordance rate
dent of zygosity. Ann Neurol 1992;32:724-7.

63 Mumford CJ, NW Wood, HF Kellar-Wood, J Thorpe, Miller D, Compston DAS. The British Isles survey of multiple sclerosis in twins. Neurology 1994;44:11-5.

64 Ebers GC, Sadovnick AD, Risch NJ. A genetic basis for familial aggregation in multiple sclerosis. Nature 1995; 377:150-1.

65 Sadovnick AD, Ebers GC, Dyment DA, Risch N, the Canadian Collaborative Study Group. Evidence for genetic basis of multiple sclerosis. Lancet 1996;347: 1728-30.

66 Robertson NP, Clayton D, Fraser MB, Deans J, Compston DAS. Conjugal multiple sclerosis. Lancet 1997 (in press).

67 Olerup O, Hillert J. HLA class II-associated genetic susceptibility in multiple sclerosis: a critical evaluation. Tissue Antigens 1991;38:1-15.

68 Seboun E, Robinson MA, Doolittle TH, Ciulla TA, Kindt TJ, Hauser SL. A susceptibility locus for multiple sclerosis is linked to the T cell receptor $\beta$ chain complex. Cell 1989:57:1095-100.

69 Wood NW, Kellar-Wood HF, Holmans P, Clayton D, Robertson N, Compston DAS. The T-cell receptor $\beta$ locus and susceptibility to multiple sclerosis. Neurology 1995;45:1859-63.

70 Walter MA, Gibson WT, Ebers GC, Cox DW Susceptibility to multiple sclerosis is associated with the proximal immunoglobulin heavy chain region. 7 Clin Invest 1991;87:1266-73.

71 Wood N, Sawcer SJ, Kellar-Wood H, Holmans P, Clayton D, Robertson N, Compston DAS. A susceptibility gene for multiple sclerosis linked to the immunoglobulin heavy chain variable region. $\mathcal{F}$ Neurol 1995;242:677-82.

72 Sawcer S, Jones HB, Feakes R, Gray J, Smaldon N, Chataway J, et al. A genome screen in multiple sclerosis reveals susceptibility loci on chromosome $6 \mathrm{p} 21$ and reveals susceptibility loci on chro

73 Ebers GC, Kukay K, Bulman D, Sadovnick AD, Rice G Anderson C, et al. A full genome search in multiple sclerosis. Nat Genet 1996;13:472-6.

74 The Multiple Sclerosis Genetics Group. A complete genomic screen for multiple sclerosis underscores a role for the major histocompatibility complex. Nat Genet 1996;13:469-71.

75 Davenport CB. Multiple sclerosis from the standpoint of geographic distribution and race. Arch Neurol 1922;8: 51-8.

76 Sutherland JM. Observations on the prevalence of multiple sclerosis in northern Scotland. Brain 1956;79:635-54

77 Chakraborty R, Kamboh, MI, Nwankwo M, Ferrell RE Caucasian genes in American blacks: new data. $\mathrm{Am} \mathcal{F}$ A $145-55$.

78 Cavalli-Sforza LL, Menozzi P, Piazza A. The history and geography of human genes. Princeton: Princeton Universty Press, 1994:541.

79 Poser CM. The dissemination of multiple sclerosis: a Viking saga? A historical essay. Ann Neurol 1994;36(suppl 2):\$231-43. 